\title{
Changes in cell size and number and in rhizodermal development contribute to root tip swelling of Hyoscyamus albus roots subjected to iron deficiency
}

Yuki Kawahara $^{1}$ and Yoshie Kitamura ${ }^{1 *}$

${ }^{1}$ Graduate School of Fisheries Science and Environmental Studies, Nagasaki University, Nagasaki, Japan

\section{Correspondence:}

Dr. Yoshie Kitamura

Nagasaki University,

Graduate School of Fisheries Science and Environmental Studies,

Laboratory of Environmental and Functional Botany

1-14 Bunkyo-machi, Nagasaki 852-8521, Japan

k-yoshie@nagasaki-u.ac.jp

tel: +81-95-819-2759 


\begin{abstract}
Root tip swelling is a common phenomenon observed when plant roots are subjected to Fe deficiency. We analysed whether an increase in cell number or an enlargement of cell width was involved in this phenomenon. Root tips of Hyoscyamus albus cultured with or without Fe were stained with fluorescent SYTO14 and analysed by confocal laser-scanning microscopy. Time-course and position-based examination revealed that the inhibition of longitudinal cell elongation and acceleration of transverse cell enlargement under Fe deficiency started from the tips and then extended towards the base during the time-course period. An increase in cell number also occurred behind the tips. In addition, the development of rhizodermal protrusions was observed on the surface of roots subjected to Fe deficiency. These results indicated that changes in cell size and number and in root hair development were all involved in root tip swelling.
\end{abstract}

Keywords: Hyoscyamus albus, root morphology, Fe deficiency, confocal laser-scanning microscopy, cell number, cell size, root hair. 


\section{Introduction}

Iron (Fe) deficiency is one of the major nutrient constraints in plant growth and development, especially in neutral and alkaline soils, due to the low solubility of abundant Fe(III) in the soil [1]. Such soils occupy about $30 \%$ of the world's land area and they are becoming more extensive, on account of over-irrigation and/or climate change. To meet the increasing demand for food supplies, the breeding of Fe deficiency-tolerant plants is a promising approach. So far, the responses of plants to insufficient levels of Fe have been studied actively in a range of crop plants and vegetables, and these studies have demonstrated the induction of the morphological and metabolic changes that are required to withstand the resultant stress and to maintain Fe homeostasis [2-9].

We have found that cultured roots of Hyoscyamus albus are able to grow under Fe deficiency; and in responding to low Fe, they secrete riboflavin into the culture medium, although they also show morphological changes, such as swelling of the root tips and increases in the numbers of lateral roots [10]. Root tip swelling is a commonly observed phenomenon when plant roots are subjected to Fe deficiency. In a cross-section of the swelling zone of sunflower root, histological and cytological investigation by Landsberg [8] revealed that the swelling was caused predominantly by isodiametric enlargement of the cortical cells, but not by an increase in cortical cell number; a longitudinal section of the swelling zone displayed complete cessation of elongation growth. On the other hand, increases in both the total number of cells per transverse section and in cell diameter in the cortex contributed to the significant enlargement of root diameter that was observed in transgenic tobacco plants that were ectopically expressing Arabidopsis basic helix-loop-helix transcription factors, which are induced under Fe deficiency [11]. In this case, no significant differences in cell length were found when longitudinal root sections were examined. Both results were apparently obtained from particular zones of the roots (usually 4 to $5 \mathrm{~mm}$ away from apex) and at particular times (in the former case, after 4 days under Fe deficiency; in the latter case, no information was provided).

In order to confirm whether cell enlargement or an increase in cell number is involved in root tip swelling in $H$. albus, and whether the longitudinal cell dimension is subject to change, we have determined both cell size and cell number at multiple points during a time course. Confocal laser-scanning microscopy has been used (to our knowledge, for the first time) to measure cell size and number in root tips subjected to Fe deficiency, without any mechanical intervention. 


\section{Materials and Methods}

\subsection{Culture methods}

Hairy roots of Hyoscyamus albus L. (Solanaceae) transformed with Agrobacterium rhizogenes ATCC15834 had been established previously [10]. Clonal hairy roots (Ha16) with $R o l B^{T L}$, but not $\operatorname{RolB}^{T R}$, derived from A. rhizogenes were used throughout the experiments. They were maintained on MS basal liquid medium [12] containing 3\% sucrose. A primary root tip with a few lateral roots (ca. $2 \mathrm{~cm}$ in length) isolated from ca. 2-week-old root cultures was subjected to Fe deficiency or to Fe-replete conditions. Fe deficiency stress was imposed by the elimination of $\mathrm{FeSO}_{4}$ and EDTA from MS basal medium, prior to autoclaving at $121^{\circ} \mathrm{C}$ for $15 \mathrm{~min}$. All cultures were maintained in 50 $\mathrm{mL}$ conical flasks containing $15 \mathrm{~mL}$ of liquid medium and were incubated at $25^{\circ} \mathrm{C}$ with agitation at $80 \mathrm{rpm}$ on a rotary shaker. Cultured roots were harvested at intervals during a 10-d time course and their root tips were taken directly for histological analysis. Experiments were repeated at least 5 times.

\subsection{Position setting and measurement by stereomicroscopy}

In order to determine root diameter, cell number and cell size, measurements were taken at 1-mm intervals, beginning at $1 \mathrm{~mm}$ from the root apex and ending at $4 \mathrm{~mm}$. Images were taken with a stereomicroscope (SZ61; Olympus Co. Japan) affixed to a digital camera (DP21; Olympus Co. Japan) and root diameters were measured using Image J software (NIH, MD, USA). In the case of cell-size measurements, the software was used after taking images using confocal microscopy, as described in section 2.3.

\subsection{Cell staining and confocal microscopy}

Root tip sections (ca. $1.5 \mathrm{~cm}$ ) from cultured roots maintained under Fe deficiency or Fe-replete conditions for various periods were isolated with a scalpel and placed in MS mineral solution. The sections were then stained with the fluorescent dye, SYTO14 (Invitrogen, USA). SYTO14 was dissolved in DMSO to be $5 \mathrm{mM}$ before addition ( $2 \mu \mathrm{l}$ ) to the MS solution (4 ml). After shaking for $10 \mathrm{~min}$ at $80 \mathrm{rpm}$, excess dye was removed 
by washing three times with MS solution. The sections were then imaged using a confocal laser-scanning microscope (FV1000D IX81; Olympus Co. Japan). Excitation and emission wavelengths were $473 \mathrm{~nm}$ and $520 \mathrm{~nm}$, respectively.

\section{Results and Discussion}

\subsection{Changes in root shape}

Root tip swelling is a typical morphological change that is observed when plant roots are subjected to Fe deficiency. Using $H$. albus roots, this change was studied over a 10 -d period of Fe deficiency, in comparison to roots maintained under Fe-replete conditions (control) (Fig. 1). A change became apparent from day 2 and became more obvious at day 5, when the most swollen region was about $1 \mathrm{~mm}$ from the apex (Fig. 1B); thereafter, the swollen zone became extended from the tip to the base, resulting in broadly-swollen root tips (about $4 \mathrm{~mm}$ in length) after $10 \mathrm{~d}$ (Fig. 1C).

Since the quiescent center was found to be at around $0.5 \mathrm{~mm}$ from the root apex, and the initial obvious change was observed at around $1 \mathrm{~mm}$ from the apex (Fig. 1B), we set the first position for imaging at $1 \mathrm{~mm}$ from the apex, denoted as a sub-meristematic zone (point 1). The next position was then set at $2 \mathrm{~mm}$ from the apex (point 2), followed by the third and fourth positions at $3 \mathrm{~mm}$ (point 3 ) and $4 \mathrm{~mm}$ (point 4) respectively, together denoted collectively as the elongation zone. Root diameters at each of these points were measured at day 1, day 5 and day 10, respectively (Fig. 2). At day 1, no apparent root size difference between the control and the $\mathrm{Fe}$ deficiency-treatment was observed for any of the measurement points, although the size at point 1 was smaller than at other points, in both cases. At day 5, the Fe-deficient root tips apparently became wider than the control root tips, both at point 1 and at point 2 ( $p<0.001$ and $p<0.01$, respectively). Furthermore, at day 10 this was the case at all four points (Fig. 2).

An increase in root tip diameter, reported as root tip swelling, has been observed previously in various plant species $[7-9,11]$. Our results obtained with $H$. albus roots cultured under Fe deficiency indicate that this swelling began in the sub-meristematic zone and gradually extended to the elongation zone.

\subsection{Changes in cell size and number}


Initially, in order to try to determine the sizes of the cells contained in the root tips, we attempted to stain the cell walls with hydrophilic Calcofluor White, but the staining was restricted to the root epidermal and sub-epidermal cells, even after vacuum infiltration. Therefore, the hydrophobic fluorescent dye, SYTO14, which is usually used to observe nuclei, was examined for their application in cell-size determination; this revealed that SYTO14 worked well in staining not only nuclei, but also cell membranes (Fig. 3).

Therefore, the tips of $H$. albus roots that had been subjected to Fe deficiency or to Fe-replete conditions for various periods were stained with SYTO14 and observed at the various designated points using the confocal laser-scanning microscope. No obvious change was found at any of the points after $1 \mathrm{~d}$ of treatment, but after $2 \mathrm{~d}$ a dramatic change appeared at point 1 in the Fe-deficient root tips. A section taken longitudinally showed that the cells had become square rather than rectangular under Fe deficiency (Fig. 3a), although a transverse section seemed not to show apparent change (Fig. 3b). Images taken orthogonally both to Fig. 3a and Fig. 3b also supported this observation (Fig. 3c). This shortening of cell length was also detected at point 2 at day 3 and at point 3 at day 5, and at all points, including point 4 , at day 7.

Cell length and width were measured at day 1, at day 5 and at day 10. The measurements revealed that, at day 5, cell length at point 1 under Fe deficiency diminished to about one third of the control values ( 1 : $29.8 \pm 7.0 \mu \mathrm{m}$, compared to $114.1 \pm 28.9 \mu \mathrm{m}$ ), and at points 2 and 3 to about one half and three quarters, respectively, of the control value (p2: $64.0 \pm 34.7 \mu \mathrm{m}$, compared to $120.9 \pm 20.0 \mu \mathrm{m}$; p3: $89.7 \pm 35.7$ $\mu \mathrm{m}$, compared to $118.5 \pm 18.9 \mu \mathrm{m}$ ), although such shortening was not found at day 1 ; after $10 \mathrm{~d}$, cell length under Fe deficiency became about one third in comparison to the control value, at all points (Table 1). On the other hand, cells gradually became wider under Fe deficiency. At day 5, cell width increased at point 1 (from $16.6 \pm 2.3 \mu \mathrm{m}$ to $24.1 \pm 3.5 \mu \mathrm{m}$ ), though not at the other three points; however, at day 10, the formation of wider cells was evident at all four points. Since it was apparent that changes in cell length and width started from point 1 and then extended towards the base of the root, cell depth was measured only at point 1 . The results showed that an increase in cell depth under Fe deficiency was not detected at day 1, but became significant at day 5 (from $12.0 \pm 2.8 \mu \mathrm{m}$ to $20.8 \pm 4.0 \mu \mathrm{m}, p<0.001$ ) (Table 1 ).

Our results indicated that the elongation of cells in roots subjected to Fe deficiency was inhibited and that instead the cells enlarged and became cubic in shape. This change started from the sub-meristematic zone and produced continuously cells of a similar type, so that after $10 \mathrm{~d}$ all the cells became cube-like at all four measurement points. Average cell volumes were calculated from these size data at point 1 (Table 1); the 
results indicated that the volumes of both a control cell and a Fe-deficient cell were around $20 \times 10^{3} \mu^{3}$ and $16 \times 10^{3} \mu \mathrm{m}^{3}$, respectively, at day 5 and thereafter. The volume of Fe-deficient cell seemed to become slightly smaller.

In order to determine whether or not changes in cell number were also involved in root tip swelling, cell numbers were counted in root section at points 1 to 4 (Fig. 4). There was a tendency for the cell number to increase in response to Fe deficiency, which was apparent at point 1 at day 5 and seen also at point 2 at day 10; and this was statistically significant at point 1 at day $10(p<0.05)$.

\subsection{Changes in rhizodermal development}

Using scanning electron microscopy, the formation of short root hairs has been observed on the surface of sugar beet root tips subjected for $10 \mathrm{~d}$ to Fe deficiency [9]. Abundant root hair formation has also been observed by electron microscopy in sunflower roots following $4 \mathrm{~d}$ of Fe-deficiency treatment [8]. It was therefore of considerable interest that, at point 1 at day 5, confocal microscopy showed the emergence of characteristic protrusions derived from rhizodermal cells in $H$. albus root tips (Fig. 5). These protrusions must presumably correspond to the root hairs reported previously.

By time-course and position-based examination together with use of confocal laser-scanning microscopy we revealed that changes in cell size and number and in root hair development were all involved in root tip swelling of $H$. albus roots subjected to Fe deficiency.

Sensing and signalling molecules regulate the induction of adaptive responses to Fe-deficiency stress, including morphological changes, although they have not been identified [13]. Plant hormones function as central regulators that link and reprogram the complex developmental and stress adaptive signalling cascades [14]. Auxins are involved in morphological changes in roots caused by Fe-deficiency stress, as indicated by the observations of increased auxin accumulation in Fe-deficient root tips [15] and changes in root morphology caused by exogenous auxin application [8, 16]. Although cultured hairy roots of $H$. albus used in this study are physiologically different from intact plant roots because the transport of systemic signals and hormones does not occur, the observed morphological and metabolic changes were highly similar [17]. Since hairy roots are autonomous tissues that produce auxins [18], and the introduction of 
TL-DNA increased the sensitivity to auxins in Nicotiana tabacum [19], auxins would be involved in signalling in $H$. albus hairy roots under Fe-deficient conditions. Auxins might induce the expression of essential transcription factors via the promotion of additional signalling compounds such as nitric oxide [15].

\section{Conclusion}

Root tip swelling is a common phenomenon observed in many plant roots, including $H$. albus hairy roots, which are coping with Fe deficiency. In this paper, we examined whether an increase in cell number or an enlargement of cell width were implicated in this phenomenon, and revealed that both changes in cell size (inhibition of longitudinal cell elongation and acceleration of transverse cell enlargement) and an increase in cell number were involved. In addition, the development of root hair-like protrusions was also observed on the surface; these changes began from the tips and then extended to the base.

To further study the relationship between sensing/signalling and downstream responses and to understand the complex mechanism of the morphological and cytological changes induced by Fe deficiency, not only intact plant roots but also $H$. albus hairy roots could be applicable. It is necessary to consider that the use of hairy roots has limitations, although.

\section{Acknowledgements}

We wish to thank Ms. Yukina Kosasa for her technical help. We also appreciate the English language editing by Dr. Nicholas Walton (Norwich, UK). This work was supported by a Grant-in-Aid (C, 24580479) from the Japan Society for the Promotion of Science. 


\section{References}

[1] Lindsay, W., Schwab, A., 1982. The chemistry of iron in soils and its availability to plants. J. Plant Nutr., 5, 821-840.

[2] Thimm, O., Essigmann, B., Kloska, S., Altmann, T., Buckhout, T. J., 2001. Response of Arabidopsis to iron deficiency stress as revealed by microarray analysis. Plant Physiol., 127, 1030-1043.

[3] Zaharieva, T., Gogorcena, Y., Abadia, J., 2004. Dynamics of metabolic responses to iron deficiency in sugar beet roots. Plant Sci., 166, 1045-1050.

[4] Rellán-Alvarez, R., Andaluz, S., Rodríguez-Celma, J., Wohlgemuth, G., Zocchi, G., Alvarez-Fernández, A., Fiehn, O., López-Millán, A.F., Abadía, J., 2010. Changes in the proteomic and metabolic profiles of Beta vulgaris root tips in response to iron deficiency and resupply. BMC Plant Biol., 10, 120.

[5] Rodríguez-Celma, J., Lattanzio, G., Grusak, M.A., Abadía, A., Abadía, J., López-Millán, A.F., 2011. Root responses of Medicago truncatula plants grown in two different iron deficiency conditions: changes in root protein profile and riboflavin biosynthesis. J. Proteome Res., 10, 2590-2601.

[6] Donnini, S., Prinsi, B., Negri, A.S., Vigani, G., Espen, L., Zocchi, G., 2010. Proteomic characterization of iron deficiency responses in Cucumis sativus L. roots. BMC Plant Biol., 10, 268.

[7] Landsberg, E.-C., 1986. Function of rhizodermal transfer cells in the Fe stress response mechanism of Capsicum annuum L. Plant Physiol., 82, 511-517.

[8] Landsberg, E.-C., 1996. Hormonal regulation of iron-stress response in sunflower roots: a morphological and cytological investigation. Protoplasma, 194, 69-80.

[9] López-Millán, A.F., Morales, F., Andaluz, S., Gogorcena, Y., Abadía, A., De Las Rivas, J., Abadía, J., 2000. Responses of sugar beet roots to iron deficiency. Changes in carbon assimilation and oxygen use. Plant Physiol., 124, 885-898.

[10] Higa, A., Miyamoto, E., ur Rahman, L., Kitamura, Y., 2008. Root tip-dependent, active riboflavin secretion by Hyoscyamus albus hairy roots under iron deficiency. Plant Physiol. Biochem., 46, 452-460.

[11] Vorwieger, A., Gryczka, C., Czihal, A., Douchkov, D., Tiedemann, J., Mock, H.P., Jakoby, M., Weisshaar, B., Saalbach, I., Bäumlein, H., 2007. Iron assimilation and transcription factor controlled synthesis of riboflavin in plants. Planta, 226, 147-158.

[12] Murashige, T., Skoog, F., 1962. A revised medium for rapid growth and bioassay with tobacco tissue cultures. Physiol. Plant., 15, 473-497.

[13] Kobayashi, T., Nishizawa, N.K., 2014. Iron sensors and signals in response to iron 
deficiency. Plant Sci., 224, 36-43.

[14] Golldack, D., Li, C., Mohan, H., Probst, N., 2014. Tolerance to drought and salt stress in plants: Unraveling the signaling networks. Front. Plant Sci., 5, 151.

[15] Chen, W.W., Yang, J.L., Qin, C., Jin, C.W., Mo, J.H., Ye, T., Zheng, S.J., 2010. Nitric oxide acts downstream of auxin to trigger root ferric-chelate reductase activity in response to iron deficiency in Arabidopsis. Plant Physiol., 154, 810-819.

[16] Giehl, R.F., Lima, J.E., von Wirén, N., 2012. Localized iron supply triggers lateral root elongation in Arabidopsis by altering the AUX1-mediated auxin distribution. Plant Cell, 24, 33-49.

[17] Khandakar, J., Haraguchi, I., Yamaguchi, K., Kitamura, Y., 2013. A small-scale proteomic approach reveals a survival strategy, including a reduction in alkaloid biosynthesis, in Hyoscyamus albus roots subjected to iron deficiency. Front. Plant Sci., 4, 331.

[18] Nemoto, K., Hara, M., Suzuki, M., Seki, H., Oka, A., Muranaka, T., Mano, Y., 2009. Function of the aux and rol genes of the Ri plasmid in plant cell division in vitro. Plant Signal. Behav., 4, 1145-1147.

[19] Maurel, C., Barbier-Brygoo, H., Spena, A., Tempé, J., Guern, J., 1991. Single rol genes from the Agrobacterium rhizogenes TL-DNA alter some of the cellular responses to auxin in Nicotiana tabacum. Plant Physiol., 97, 212-216. 


\section{Figure Legends}

Figure 1. Changes in root tip morphology under Fe deficiency.

H. albus roots were treated with and without Fe for $10 \mathrm{~d}$. A, day 1; B, day 5; C, day 10; left side, with Fe (control); right side, without Fe (-Fe). Bars indicate $1 \mathrm{~mm}$ in length.

Figure 2. Changes in diameter of root tips subjected to Fe-deficient and Fe-replete conditions.

Root diameters were measured at points 1, 2, 3 and 4 during a 10-d time course. Data are means and SD of 7 samples. Data were analyzed by ANOVA and by Student $t$-test. ** and *** denote significant differences at the levels of $\mathrm{p}<0.01$ and $\mathrm{p}<0.001$, respectively, compared with the control.

Figure 3. Confocal laser-scanning microscopic images of $H$. albus root tip sections. Images were captured from point 1 of root tips subjected to Fe-replete conditions (control) and Fe deficiency (-Fe) for 2 d after staining with SYTO 14 (x 200). a, a longitudinal section; $\mathbf{b}$, a transverse section; c, a section orthogonal both to a and $\mathbf{b}$.

Figure 4. Cell numbers measured in transections of root tips subjected to Fe- deficient and Fe-replete conditions.

Root cell number was counted at points 1, 2, 3 and 4 during a 10-d time course. Data are means and SD of 5 samples. Data were analyzed by ANOVA and by Student $t$-test. * denotes a significant difference at the level of $\mathrm{p}<0.05$, compared with the control.

Figure 5. Confocal laser-scanning microscopic images of $H$. albus root tip surface.

Images were captured from point 1 of root tips subjected to Fe-replete (control) and Fe-deficient (-Fe) conditions for 5 d after staining with SYTO14 (x 200). 
Figure 2.
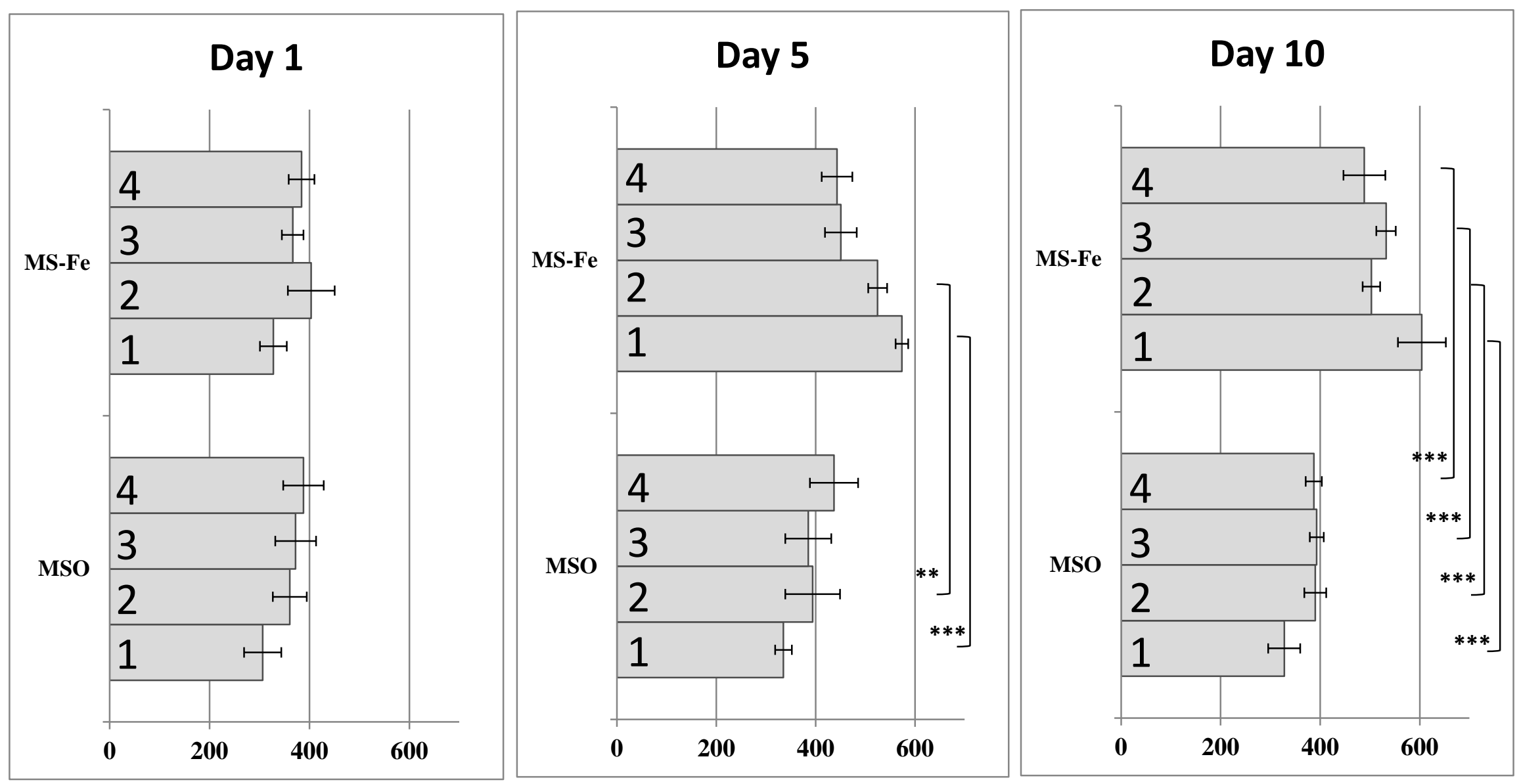
Figure 3.
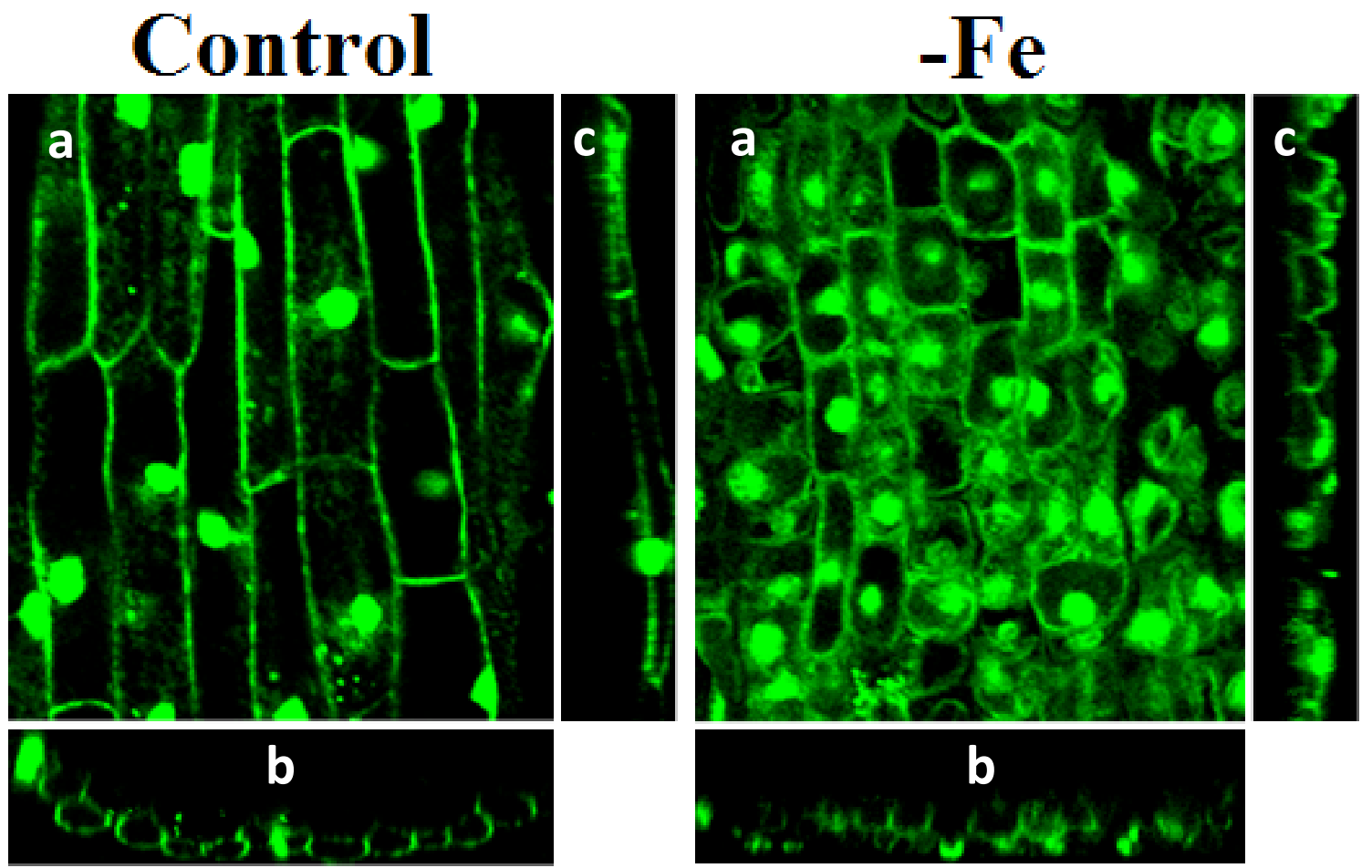
Figure 4.
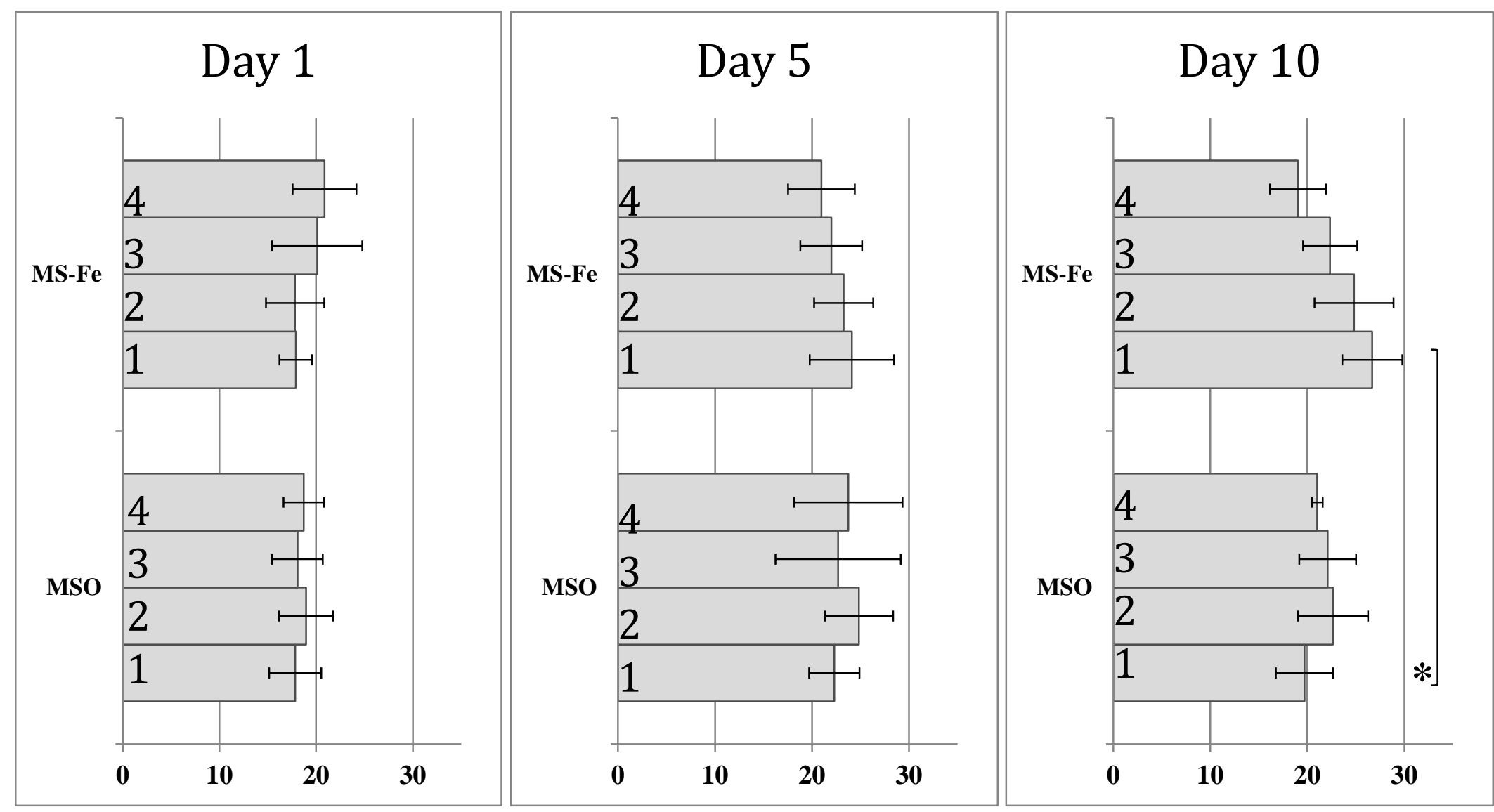
Figure 5.

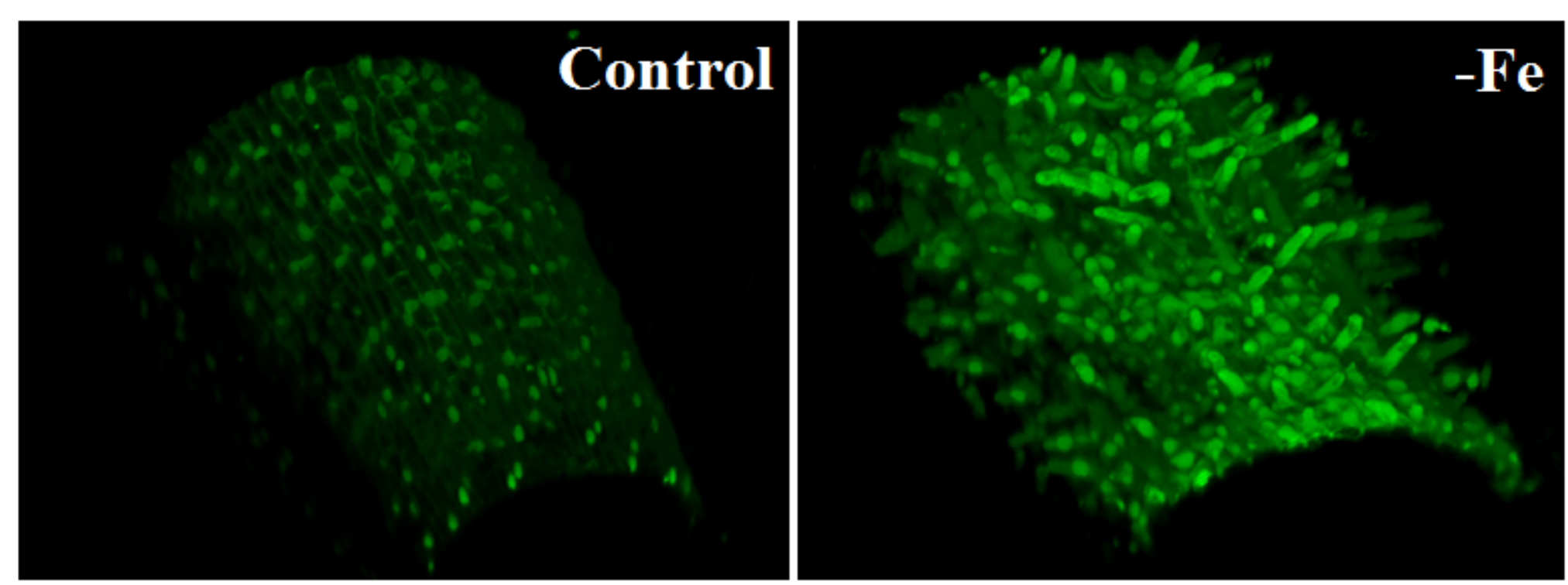


Table 1. Cell sizes of $H$. albus root tips subjected to Fe-deficient (-Fe) and Fe-replete (control) conditions, determined at four measurement points (see text below).

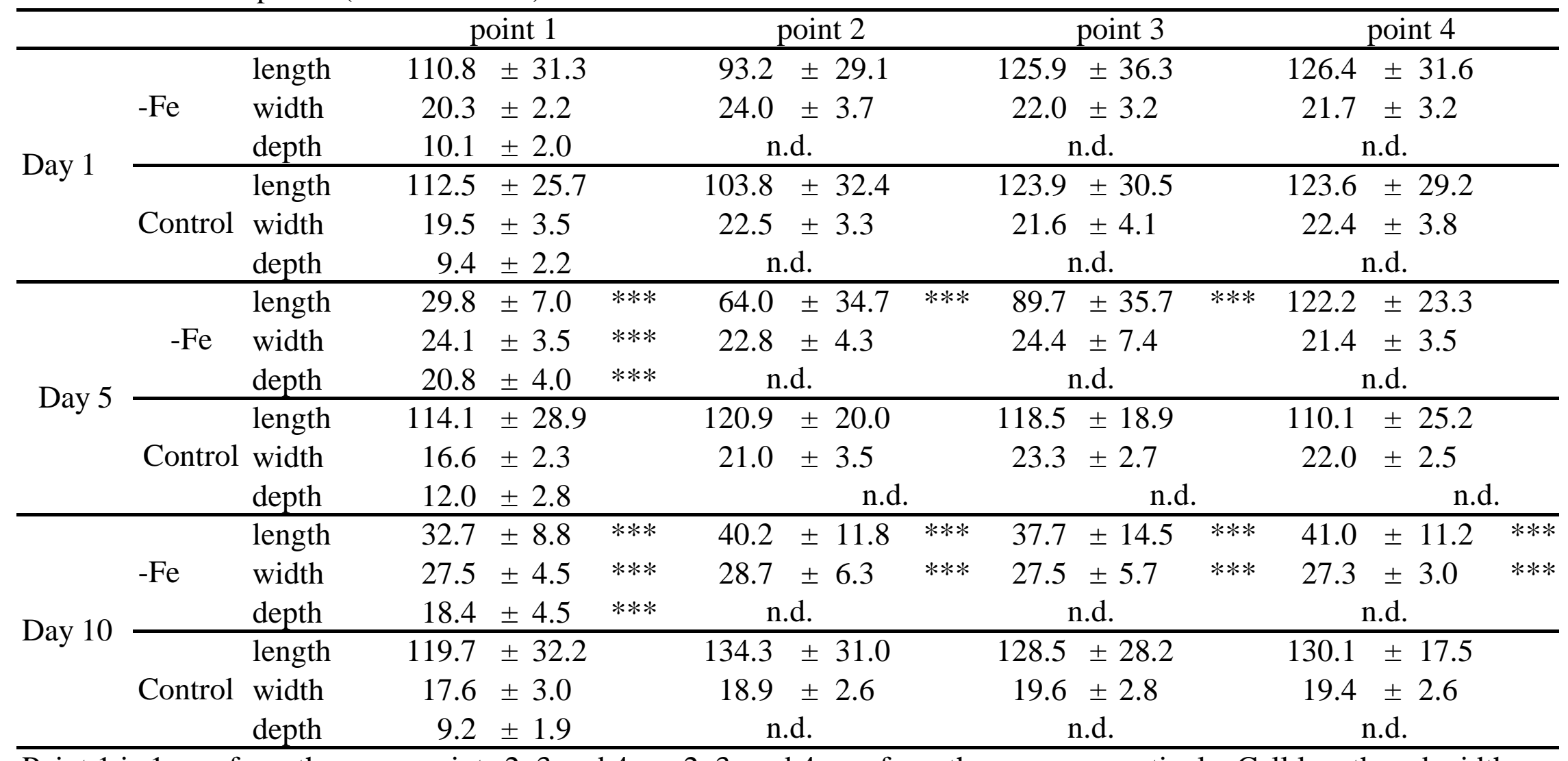

Point 1 is $1 \mathrm{~mm}$ from the apex; points 2, 3 and 4 are 2, 3, and $4 \mathrm{~mm}$ from the apex, respectively. Cell length and width were measured at all points at day 1, day 5 and day 10, whereas cell depth was measured only at point 1 at day 1 and day 10. n.d., not determined. Data are means and SD of 5 samples (in total more than 50 cells). Data were analyzed by ANOVA and by Student t-test. $* * *$ denotes a significant difference at the level of $\mathrm{p}<0.001$, compared with the control. 